\title{
Morphological and ontogenetic studies on the gynostemium of some Australian members of Diurideae and Cranichideae (Orchidaceae)
}

\author{
H. Kurzweil1 ${ }^{1}$ P.H. Weston ${ }^{2}$ and A.J. Perkins ${ }^{2}$ \\ ${ }^{1}$ Compton Herbarium, South African National Biodiversity Institute, 7735, Claremont, \\ South Africa. To whom correspondence regarding reprints should be addressed. \\ ${ }^{2}$ National Herbarium of New South Wales, Royal Botanic Gardens Sydney, Mrs. Macquarie's \\ Road, Sydney, NSW 2000, Australia.
}

\begin{abstract}
Gynostemium development of Genoplesium fimbriatum (Orchidaceae-Diurideae) is described and documented by means of SEM micrographs. Other Australian representatives of tribes Diurideae and Cranichideae are briefly treated. Particular attention is paid to the early stages which are essential for the correct interpretation of the gynostemium structure. It was found that gynostemium development largely conforms to that of the other Orchidaceae that have been examined in this respect. Several of the species have auricles (filament appendages) next to the anther and a shallowly or prominently three-lobed median stigma lobe in middle ontogeny which are both interesting similarities shared with tribes Orchideae and Diseae. As in the latter two tribes, the mature lateral gynostemium appendages ('column-wings') of some of the study species are of dual origin, comprising both a staminodial and an auricular element.
\end{abstract}

\section{Introduction}

The available literature on the Australian terrestrial orchids consists mainly of floristic, taxonomic and phylogenetic studies. Although a limited amount of information on the flower structure of many species can be obtained in the existing literature, little detailed work on floral morphology has been carried out on a broad scale. A notable exception is the careful study of Rasmussen (1982) who described gynostemium structure and development of a few Australian terrestrial orchids in great detail. Very recently detailed information on the flower morphology and ontogeny of Calochilus has been made available (Perkins 2001).

In the present paper gynostemium development in Genoplesium fimbriatum (= Prasophyllum fimbriatum) is described in detail and that of several other Australian terrestrial orchids is more briefly characterised. Ontogenetic information on a few more superficially studied species is summarised in a table. Development was found to be basically similar to that described in other orchids where it has been more fully described (Kurzweil 1987a-b). The species examined here represent most subtribes of 
tribe Diurideae and subtribe Pterostylidinae of tribe Cranichideae (all taxa sensu Pridgeon et al. 2001, 2003; see Table 1). Special attention is paid to the early and middle development of the gynostemium - here defined as comprising the ontogeny before the stage where the column-part (if present) starts elongating, or up to the stage where the stigma starts becoming papillose. An understanding of this particular phase is essential for a correct interpretation of the adult gynostemium architecture. While the examination of a few selected species is obviously insufficient as a character survey in large groups, the present paper is intended as a preliminary analysis and is furthermore aimed at stimulating future research. It is hoped that comparative investigations of a large number of species will be undertaken one day, with the aim of improving our understanding of the fascinating flowers of these orchids and thereby contributing characters for phylogenetic analysis. The results presented here reveal similarities shared by at least some members of all tribes of Orchidoideae that have been examined for floral development. Interestingly, these have a similar phylogenetic distribution to some other morphological features (e.g. root tubers; Dressler 1981, 1993). Recent molecular studies (e.g. Cameron et al. 1999; Kores et al. 2000, 2001; Clements et al. 2002) provide a robust phylogenetic framework within which the evolution of these features can be interpreted.

Ontogeny is probably the best criterion for recognising primary homology (de Pinna 1991) and frequently a reasonable homologisation of organs is not possible without a sound knowledge of their development. Ontogenetic studies have also proven useful in botany and zoology in sometimes allowing the relative generality of homologous character states to be observed directly (Weston 1988, 1994). Furthermore, ontogeny can also contribute valuable taxonomically significant characters. We expect that our knowledge of the phylogeny and morphological evolution of the Australian terrestrial orchids will benefit greatly from a better understanding of its floral and especially gynostemium structure and development.

\section{Material and methods}

Most of the plant material was collected directly in the field in New South Wales (Australia) by the second author. It was preserved in FAA (ethanol 70\% : glacial acetic acid : formaldehyde $=18: 1: 1$ ) and subsequently transferred to $70 \%$ ethanol. The exact sources of the material are given in the appendix.

For the present SEM investigations the material was prepared in ethanol $70 \%$ under a dissecting microscope. Samples were chemically dehydrated in FDA (= formaldehydedimethylacetal) and subsequently critical-point-dried directly from FDA without the use of an intermedium, using $\mathrm{CO}_{2}$ as the carrier gas (technique after Gerstberger \& Leins 1978). The dry samples were coated with AuPd in a 'BALZERS' sputter-coater and viewed and photographed in a CAMBRIDGE STEREOSCAN S200 scanning electron microscope at $10 \mathrm{kV}$.

The terminology used here follows that published in earlier papers of the first author (particularly in Kurzweil 1987a-b). 
Table 1. Systematic distribution of the species studied among the Australian representatives of Diurideae and Cranichideae, and the extent of our investigation.

The classification follows Pridgeon et al. $(2001,2003)$ : early ontogeny ... up to the three-carpel-apex stage; middle ontogeny ... up to the start of the elongation of the column-part (if present) or up to the stage where the stigma starts becoming papillose; late ontogeny ... up to anthesis. The figure gives the number of different stages observed.

Taxon

TRIBE DIURIDEAE

Subtribe Acianthinae

Acianthus fornicatus

Corybas fimbriatus

Subtribe Caladeniinae

Caladenia carnea

C. catenata

Eriochilus autumnalis

Glossodia minor

Subtribe Cryptostylidinae

Cryptostylis erecta

Subtribe Diuridinae

Diuris longifolia

Orthoceras strictum

Subtribe Drakaeinae

Caleana major

Chiloglottis sp.

Subtribe Megastylidinae

Lyperanthus suaveolens

Rimacola elliptica

Subtribe Prasophyllinae

Microtis parviflora

Genoplesium fimbriatum

Subtribe Rhizanthellinae

Subtribe Thelymitrinae

Calochilus campestris

C. roberstsonii

Thelymitra carnea

TRIBE CRANICHIDEAE

Subtribe Goodyerinae

Subtribe Pterostylidinae Pterostylis concinna

Subtribe Spiranthinae
Total

\section{Ontogeny}

\section{early middle late}

12

1

1

4

4

20

12

22

16

4

2

13

8

14

4

13

15

3

-

$-$

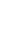$$
-
$$$$
7
$$

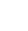$$
1
$$$$
-
$$

36

$1-7$

$\begin{array}{ll}- & 1 \\ - & 1\end{array}$

- 1$$
\text { - } 4
$$

9

$\begin{array}{ll}7 & 4\end{array}$

193

6

43

$20 \quad 11$

3
11

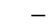




\section{Observations}

Table 2. Various features observed in the species studied: Ic ... lateral carpel apices/stigma lobes; mc ... median carpel apex/stigma lobe.

The ontogenetic stages correspond to those defined in Table 1. $\mathrm{x}=$ character present, $(\mathrm{x})=$ character obscure/weakly developed, - = character not present, ? = not clear, 0 = stages not observed, sep = separate, con = connate to a ridge, emarg = connate to an emarginate ridge .

\begin{tabular}{|c|c|c|c|c|c|c|c|}
\hline \multirow{2}{*}{$\begin{array}{l}\text { Taxon } \\
\text { (in brackets numbers of } \\
\text { illustrations in the present paper) }\end{array}$} & \multicolumn{2}{|c|}{ Staminodes } & \multicolumn{2}{|c|}{ Auricles } & \multicolumn{2}{|l|}{ Ic } & \multirow{2}{*}{$\begin{array}{l}\text { mc } \\
\text { (middle stage) }\end{array}$} \\
\hline & $\begin{array}{l}\text { early/ } \\
\text { middle I }\end{array}$ & late & middle & late & middle & late & \\
\hline Acianthus fornicatus (Fig. 7A-D) & $x$ & $x$ & - & - & con & con & clearly 3-lobed \\
\hline Caladenia carnea & 0 & $x$ & 0 & 0 & 0 & emarg & 0 \\
\hline C. catenata (Fig. 5D) & 0 & $x$ & 0 & 0 & 0 & emarg & 0 \\
\hline Caleana major (Fig. 3D-F) & $x$ & $x$ & - & $x ?$ & 0 & emarg & obscurely 3-lobed \\
\hline Calochilus campestris (Fig. 6) & $x$ & $x$ & $(x)$ & $x$ & con & con & clearly 3-lobed \\
\hline C. robertsonii & 0 & 0 & 0 & $x$ & 0 & 0 & 0 \\
\hline Chiloglottis sp. (Fig. 5E) & 0 & $x$ & - & - & 0 & 0 & 0 \\
\hline Corybas fimbriatus (Fig. 5F-H) & 0 & $x$ & - & - & 0 & emarg & clearly 3-lobed \\
\hline Cryptostylis erecta (Fig. 4A-B) & $x$ & $x$ & - & - & sep & emarg & unlobed \\
\hline Diuris longifolia (Fig. 4C-E) & $x$ & $x$ & - & $?$ & con & con & unlobed \\
\hline Eriochilus autumnalis & 0 & $?$ & 0 & - & 0 & emarg & 0 \\
\hline $\begin{array}{l}\text { Genoplesium fimbriatum } \\
\text { (Fig. 1A-H, 2A-C) }\end{array}$ & $x$ & $x$ & $x$ & $x$ & sep & emarg & obscurely 3-lobed \\
\hline Glossodia minor & 0 & $x$ & 0 & - & 0 & 0 & 0 \\
\hline Lyperanthus suaveolens (Fig. 5I) & 0 & $x$ & 0 & $x$ & 0 & emarg & 0 \\
\hline Microtis parviflora & $x$ & $x$ & - & - & 0 & con & obscurely 3-lobed \\
\hline Orthoceras strictum (Fig. 4F-I) & $x$ & $x$ & $(x)$ & $?$ & sep & emarg & obscurely 3-lobed \\
\hline Pterostylis concinna (Fig. 7E-I) & $x$ & $x$ & $(x)$ & $(\mathrm{x})$ & sep & sep & obscurely 3-lobed \\
\hline Rimacola elliptica (Fig. 3A-C) & $x$ & $x$ & $(x)$ & $x$ & emarg & emarg & unlobed \\
\hline Thelymitra carnea (Fig. 5A-C) & $x$ & $x$ & $(x)$ & 0 & emarg & 0 & unlobed \\
\hline
\end{tabular}

\section{Genoplesium fimbriatum (R. Br.) D.L. Jones \& M.A. Clem.}

Commonly called 'Midge Orchid', the genus Genoplesium (tribe Diurideae) comprises about forty species in open situations in sclerophyllous forest and heathland in Australia (particularly in the south-eastern areas), New Zealand and New Caledonia. Vegetative as well as floral morphological features mark affinities to Prasophyllum in which genus Genoplesium was included in the past. All species are sympodial herbs with root tubers and have a single terete and hollow leaf (Jones 2001). The inflorescence bursts through the leaf at a predetermined point near its tip. Flowers are non-resupinate and have a mobile lip. Pollination is mainly carried out by small flies of the superfamily Chloropoidea, which may be attracted by nectar, fruity perfumes or mobile lips (Bower 2001). A few species are self-pollinating. Molecular phylogenetic analyses of small samples of species (Kores et al. 2001; Clements et al. 2002) suggest that Genoplesium s.l. is paraphyletic to Prasophyllum s.s.. Jones et al. (2002) transferred G. fimbriatum and 45 other species to the genus Corunastylis on the basis of these results. However, we prefer to retain the existing taxonomy until more species in the Prasophyllinae have been phylogenetically analysed and relationships are more clearly resolved. 

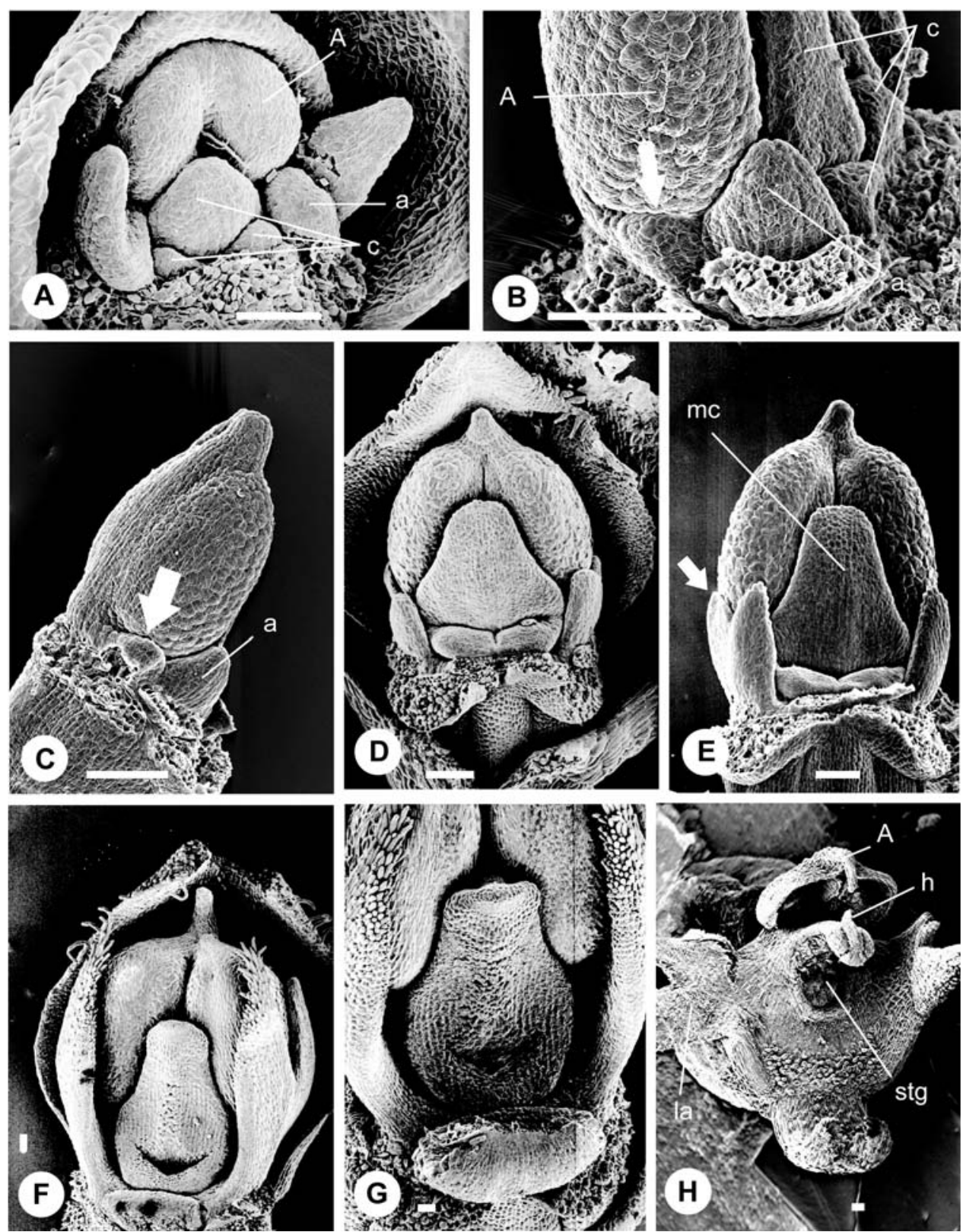

Fig. 1. Genoplesium fimbriatum; gynostemium development. A, D-F, Front views of the gynostemium in different stages. B-C, Base of gynostemium and whole gynostemium in side view. $\mathbf{G}$, Stigma in a late stage seen from the front. $\mathbf{H}$, Adult anther-stigma-complex, lateral gynostemium appendages (column-wings) largely removed. — SEM micrographs. Bars: $0.1 \mathrm{~mm}$. Abbreviations: $\mathrm{A}=$ anther, $\mathrm{a}=$ staminodes, $\mathrm{c}=$ carpel apices, $\mathrm{h}=$ hamulus, $\mathrm{la}=$ lateral gynostemium appendages, $\mathrm{mc}=$ median carpel apex, stg $=$ stigma. The arrowheads mark suspected auricles $(=$ filament appendages; see Kurzweil 1987b). Source: Weston 1277. 
Genoplesium fimbriatum, the 'Fringed Midge Orchid', is endemic to south-eastern Queensland and the coastal areas of New South Wales where it is rather common in suitable habitats. Its flowers measure about $9-11 \mathrm{~mm}$ across and are prominently hairy. Sepals and petals are yellowish green with red stripes and the lip is generally pale red. The ovate median sepal is hooded and has long marginal cilia, and the divergent or spreading lateral sepals are linear to lanceolate in shape and have entire margins. Cilia are also present on the narrowly ovate or ovate and pointed petals. A characteristic feature of the species is the linear lip which is hinged on a short strap and has many long pink or red marginal cilia which tremble in the wind. It is conspicuously recurved at its apex and has a long median callus consisting of two narrow ridges. The stout gynostemium (Fig. 1H) lacks a long column-part and has a pronounced basal columnfoot. Its most prominent organs are the erect column-wings which are approximately as tall as the anther. They are deeply two-lobed and basally fused to the anther-stigmacomplex. The erect anther is comparatively narrow, measuring about one third of the gynostemium. An elongate, apical connective process is visible on top of the anther. The entire stigma is papillose and funnel-shaped.

In the earliest stage available (Fig. 1A) the anther is erect and its division into two thecae is made visible by a prominent gap between them which is especially pronounced in its lower part. All three carpel apices have already emerged with the median one being the largest. The latter is an erect and entire lobe in front of the anther. The two lateral carpel apices are separate structures in front of the median carpel apex. Prominent bulges are visible at the inner base of the petals, i.e. in a position superposed to them (a in Fig. 1A). On account of their position and their early initiation they are here interpreted as vestiges of the staminodes $a_{1}$ and $a_{2}$ which corresponds well with the situation in other groups of monandrous Orchidaceae (Kurzweil 1985, 1987a). They will be simply referred to as 'staminodes' below.
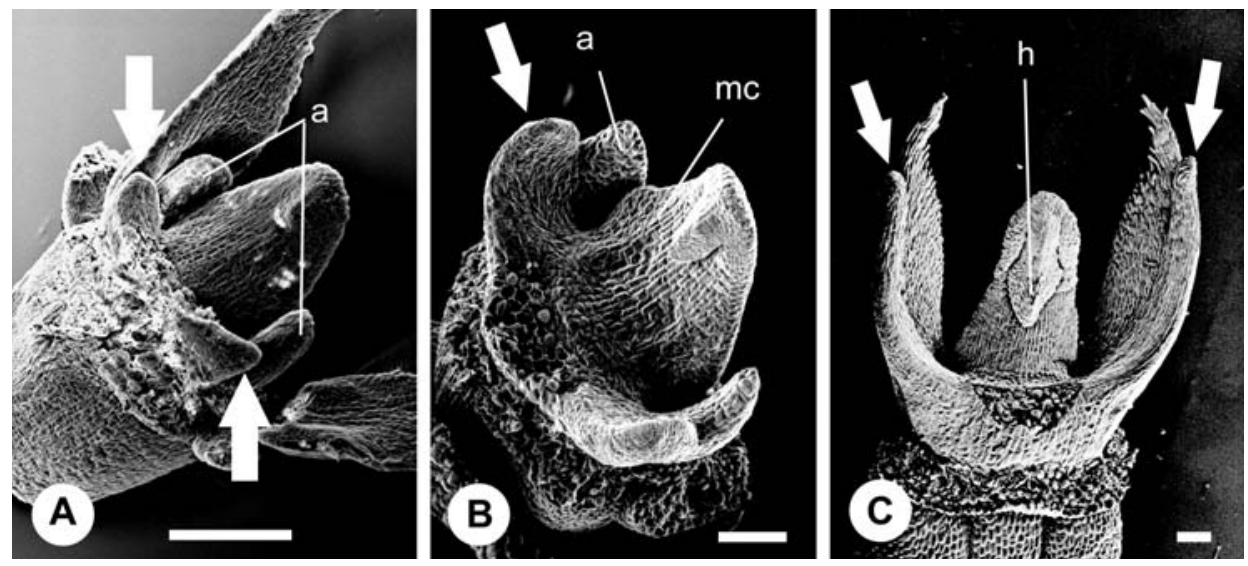

Fig. 2. Genoplesium fimbriatum; gynostemium in different developmental stages with the anther removed, showing the median carpel apex, the staminodes and the suspected auricles. A-B, side views; C, dorsal view. - SEM micrographs. Bars: $0.1 \mathrm{~mm}$. Abbreviations: a = staminodes, $\mathrm{h}=$ hamulus, $\mathrm{mc}=$ median carpel apex. The arrowheads mark suspected auricles (= filament appendages; see Kurzweil 1987b). Source: Weston 1277. 
These staminodes later grow into the anterior lobes of the prominent two-lobed wings next to the anther (Fig. 1D-H). In slightly later stages additional structures appear as small but clearly visible bulges, emerging in a dorsolateral position on the anther (arrowheads in Fig. 1B-C). They obviously do not occupy a position superposed to the petals and are thus distinct from the staminodes. They are also not simply posterior outgrowths of the staminodes which one would expect to develop late in ontogeny. It is here suggested that the dorsolateral structures in question are appendages of the filament of the anther, constituting auricles comparable to those in Orchideae (Kurzweil 1987b). The further development of these auricles is also visible in gynostemia where the anther has been removed (arrowheads in Fig. 2A-C). Later in ontogeny they become basally fused with the staminodes and grow up together with them while their common base elongates. The prominent lateral gynostemium appendages ('column-wings' in taxonomic and floristic treatments) are thus of dual origin as in some other Orchidaceae (see discussion), being derived from both lateral staminodes of the inner staminal whorl and filament appendages of the fertile anther (termed auricles). Rather early, the median carpel apex develops into an obscurely three-lobed organ (Fig. 1D-G). The lateral carpel apices become fused at their base and the resulting ridge-like structure remains significantly emarginate. Its derivation from two separate structures is thus clearly visible.

In middle and late ontogenetic stages the staminodial (= anterior) portions of the lateral gynostemium appendages become pointed and minutely lacerate (Fig. 1F, 2C). The posterior auricular portions remain rounded and oblong lobes and their surface remains smooth throughout ontogeny. In middle and late stages they are slightly shorter than the staminodial portions (Fig. 2C). The three carpel apices form an oval pad with a flat front face in late development (Fig. 1G), and the median carpel apex is by far the largest of the three carpel apices. It is a long erect tongue-like lobe. As in other monandrous orchids the rostellum of the mature gynostemium is entirely derived from the upper part of this organ. Its apical portion develops into a prominent hamulus-type stipe (sensu Rasmussen 1982) (Fig. 1H, 2A-C). The lower portion of the median carpel apex and the two lateral carpel apices become conspicuously papillose (Fig. 1G). They eventually form the receptive stigma surface and are thus referred to as the stigma lobes. In late stages the lower portion of the anterior part of the funnel-rim which is derived from the lateral stigma lobes grows forward (Fig. 1H). The prominent elongate apical connective process of the anther develops in late ontogenetic stages.

\section{Notes on other species}

\section{Rimacola elliptica (R. Br.) Rupp}

Rimacola elliptica, the sole species of its genus, is endemic to the Sydney region, including the Blue Mountains (New South Wales). It is most closely related to the monotypic New Zealand genus Waireia (Clements et al. 2002), which, together, were originally included in the rather more distantly related genus Lyperanthus (Kores et al. 2001). The arching inflorescences bear a few resupinate flowers with narrowly lanceolate sepals, falcate petals, and an unlobed or obscurely three-lobed lip with a basal callus. The mature gynostemium has a long column-part and prominent column-wings are present. The apex of the anther is broadly rounded in the early and middle developmental stages but exhibits a short subacute connective process in late stages (Fig. 3C). Prominent staminode primordia are visible in early stages 
(a in Fig. 3A) and later develop into the obscure column-wings ( $\mathrm{a}$ in Fig. 3C). In addition, obscure bulges probably homologous with auricles are developed in middle stages (arrowhead in Fig. 3A) and grow into the posterior portion of the shallowly twolobed lateral gynostemium appendages that are visible in the late stages (arrowhead in Fig. 3B). In the mature flower the suspected auricles are visible as small dorsolateral teeth next to the anther (arrowhead in Fig. 3C). The median carpel apex is unlobed in all stages observed (not shown). The initiation of the lateral carpel apices was not observed but a slightly later stage reveals that they are partly fused to an emarginate ridge (not shown).

\section{Caleana major R. Br.}

Caleana is a small genus in eastern Australia and New Zealand. C. major has erect inflorescences with a few non-resupinate flowers. The median sepal is hood-like while the lateral sepals are linear and reflexed. A most conspicuous part of the flower is the duck's head-shaped lip. The gynostemium is very prominent with its wide column-
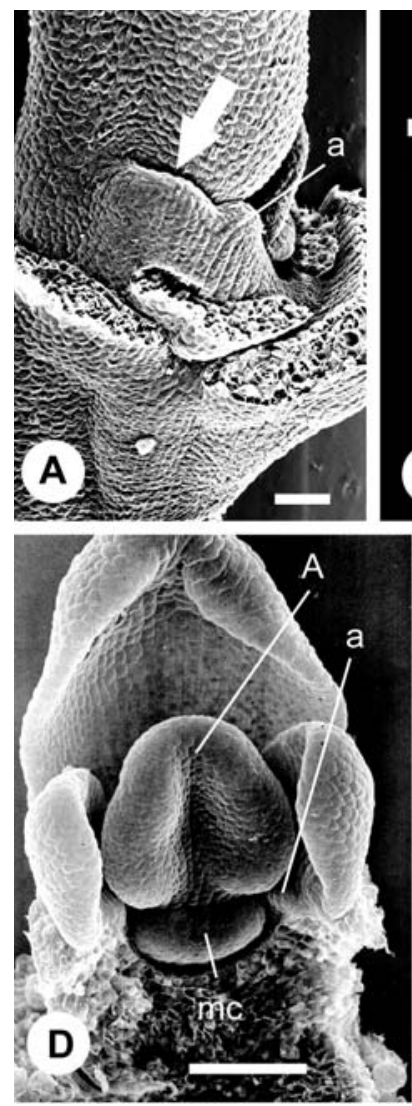
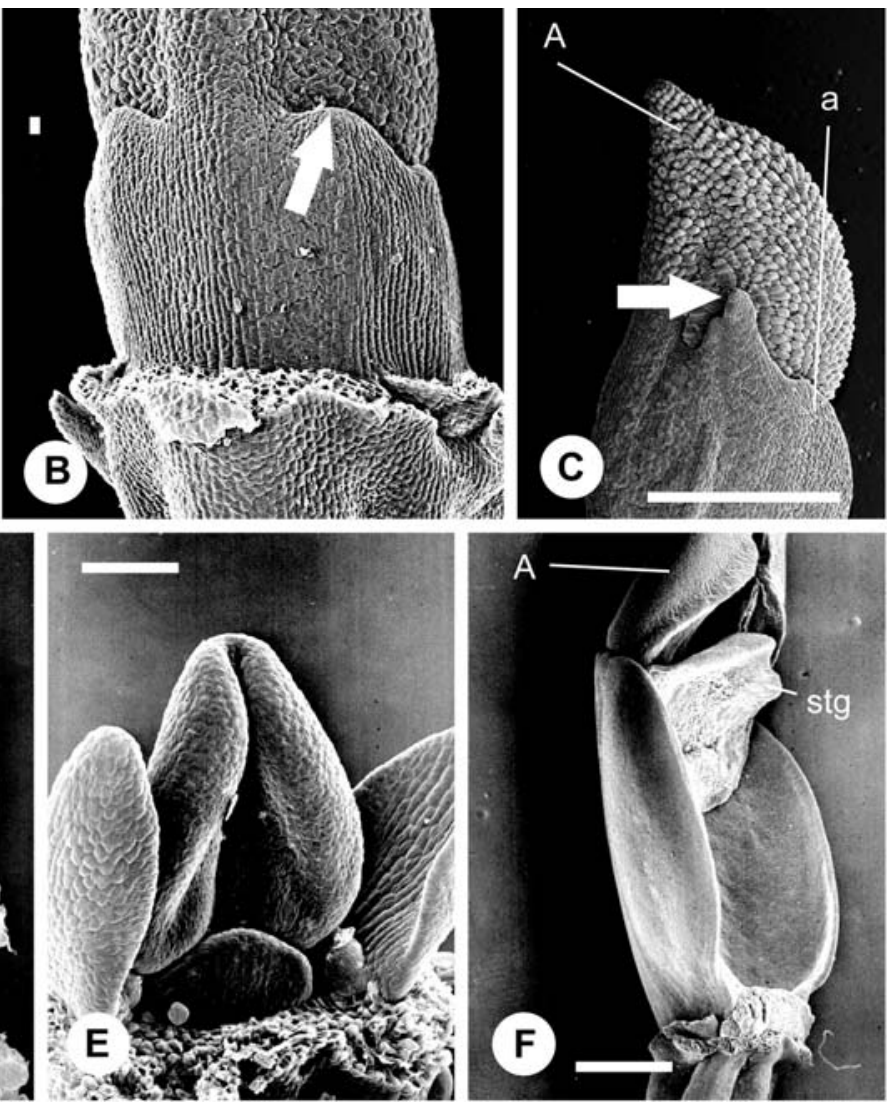

Fig. 3. Gynostemium development of various species. A-C, Rimacola elliptica, side/dorsal views; D-F, Caleana major, front views. - SEM micrographs. Bars: $0.1 \mathrm{~mm}$ in A-B, D-E; $1 \mathrm{~mm}$ in C, F. Abbreviations: $\mathrm{A}=$ anther, $\mathrm{a}=$ staminodes, $\mathrm{mc}=$ median carpel apex, stg = stigma. The arrowheads mark suspected auricles (= filament appendages; see Kurzweil 1987b). Sources: a-b: Weston 1586; c: Bishop J67/31-37; d-f: Weston 1229. 
wings, " ... so broad that they form an inverted cup-like basket" (Bernhardt 1993: 194). In the mature flower these column-wings extend over the full length of the columnpart while in other orchids marked column-wings are confined to the upper portion of the column-part (for example in Rimacola elliptica). In early ontogeny staminode primordia are clearly visible ( $\mathrm{a}$ in Fig. $3 \mathrm{D}$ ), and later develop into the prominent column-wings of the adult gynostemium (Fig. 3F). The anther is somewhat narrow and pointed in e-arly and middle ontogeny (Fig. 3E). No prominent additional lateral or dorsolateral gynostemium appendages are visible in early or middle ontogenetic stages. However, an obscure tooth on the side of the gynostemium is visible in a late stage (illustrated in Kurzweil 1998, Fig. 11D). The present investigations are inconclusive with regard to the ontogenetic derivation of the tooth, but the presence of staminodial column-wings and dorsolateral gynostemium teeth may suggest a dual origin of the lateral gynostemium appendages from staminodes and auricles like in many other orchids. The median carpel apex is obscurely three-lobed in middle and late stages (not shown).

\section{Cryptostylis erecta R. Br.}

Cryptostylis is a primarily Australasian genus of about twenty species. The erect inflorescences bear a few non-resupinate flowers with linear sepals and petals and a large ovate-oblong lip. The gynostemium development of C. erecta (endemic to Queensland, New South Wales and Victoria) has been briefly examined. In middle stages prominent staminode primordia occur (Fig. 4A). Structures likely to be auricles were not observed in any stage. In late stages the lateral appendages are several-toothed lobes (Fig. 4B), and their lobed appearance may suggest that they incorporate auricular tissue as in many other orchids. The median carpel apex is a large erect, entire lobe and is strongly bulging to the front (Fig. 4A). The stigma is an erect pad with the papillose area derived from all three stigma lobes. Lateral carpel apices are separate structures at their time of initiation (not shown).

\section{Diuris longifolia R. Br.}

The genus Diuris ( \pm 55 species, Jones 2001) is amongst the most attractive of the Australian terrestrial orchids with their fairly large resupinate flowers. The slender lateral sepals are mostly reflexed while the median sepal is developed as a shallow hood. Most prominent are the ear-like clawed petals. The gynostemium lacks a basal columnpart as anther, style and column-wings are free-standing structures and are only fused at their base. Only a few developmental stages of the Western Australian D. longifolia were available for study. The large erect lateral appendages of the mature gynostemium arise from prominent staminode primordia that are visible in early ontogeny (Fig. 4C). Auricles are not visible in any early or middle stage. However, the lateral appendages of the gynostemium are shallowly two-lobed in late stages which may point to a dual origin of the lateral appendages from staminodes and auricles. The median carpel apex is unlobed in all stages (Fig. 4C-E). In middle stages it is somewhat infolded in its central portion which grows into the gap between the two thecae (Fig. 4D), and in late ontogeny this central portion forms the viscidium. The lateral carpel apices emerge connate as an undivided edge (Fig. 4C). 

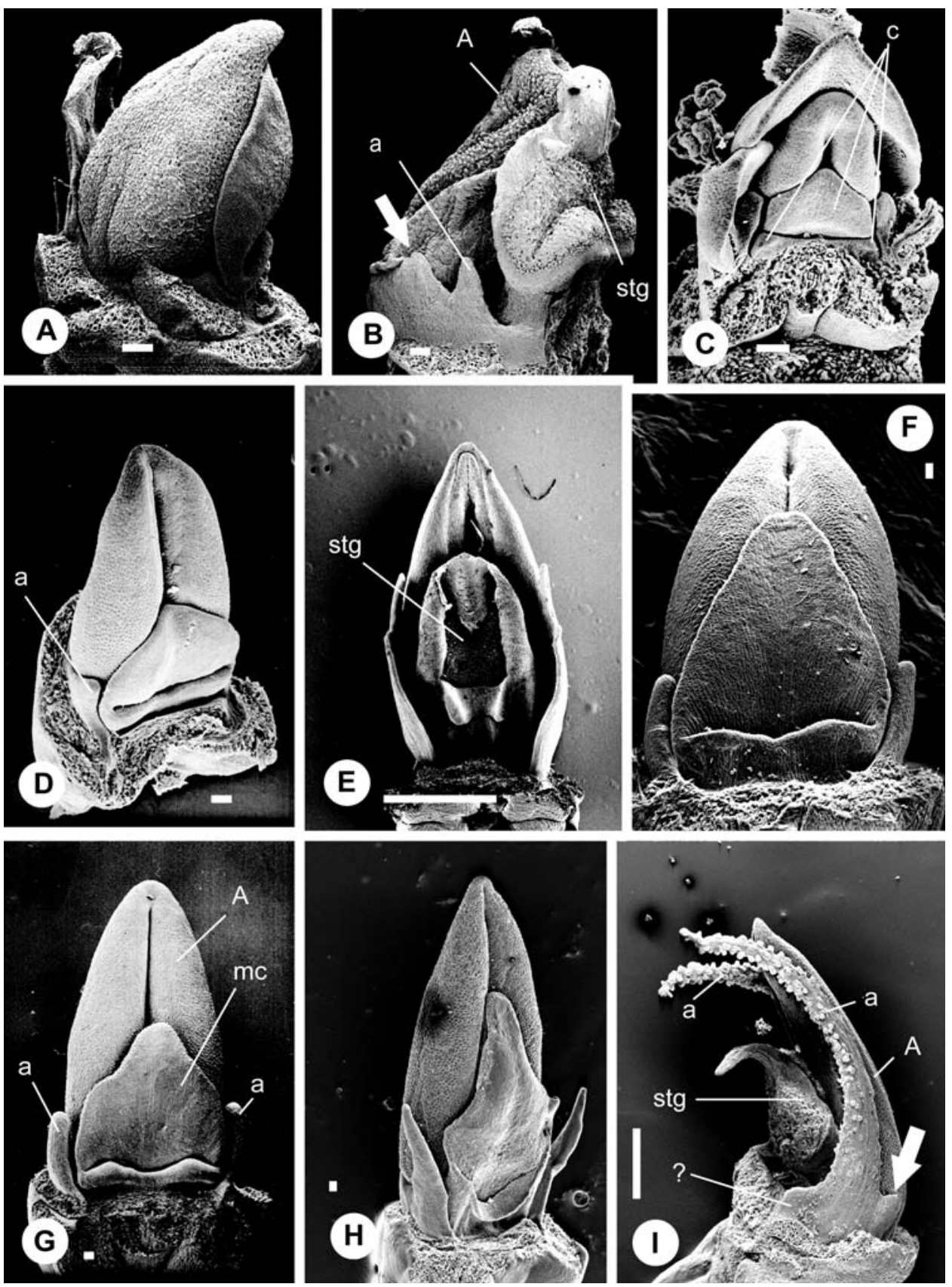

Fig. 4. Gynostemium development of various species. A-B, Cryptostylis erecta, side views; C-E, Diuris longifolia, front views; F-I, Orthoceras strictum. F-H, front views; H, three-quarter view; I, adult gynostemium in side view. - SEM micrographs. Bars: $0.1 \mathrm{~mm}$ in A-D, F-H; $1 \mathrm{~mm}$ in E, I. Abbreviations: $\mathrm{A}=$ anther, $\mathrm{a}=$ staminodes, $\mathrm{c}=$ carpel apices, $\mathrm{mc}=$ median carpel apex, $\mathrm{stg}$ = stigma. The arrowheads mark suspected auricles (= filament appendages; see Kurzweil 1987b). Sources: A-B: Weston 2473; C-E: sine collector; F, H: Weston 1584; G: Weston 1271; I: Weston 1279. 

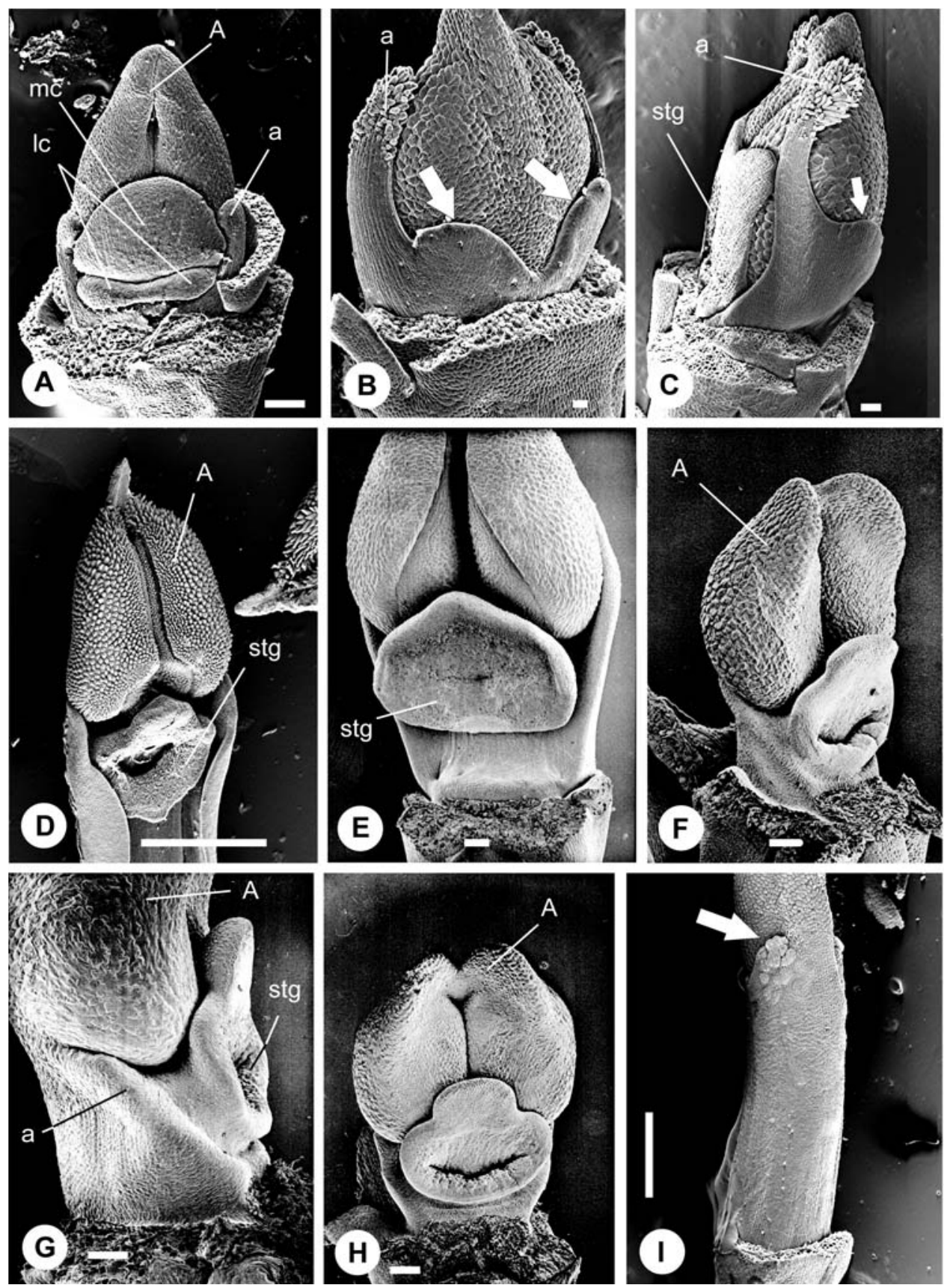

Fig. 5. Gynostemium development of various species. For reference see Table 2. A-C, Thelymitra carnea. A, front view; B, dorsal view; C, side view; D, Caladenia catenata, front view; E, Chiloglottis sp., front view; F-H, Corybas fimbriatus. F-G. side views; $\mathrm{H}$, front view; - i, Lyperanthus suaveolens, dorsal view. - SEM micrographs. Bars: $0.1 \mathrm{~mm}$ in A-C, E-H; $1 \mathrm{~mm}$ in D, I. Abbreviations: $\mathrm{A}=$ anther, $\mathrm{a}=$ staminodes, $\mathrm{lc}=$ lateral carpel apices, $\mathrm{mc}=$ median carpel apex, stg = stigma. The arrowheads mark suspected auricles (= filament appendages; see Kurzweil 1987b). Sources: A: Weston 1227; B-C: Weston 1232; D: Abell 67; E: Weston 1278; F-H: Weston 1392; I: Weston 1224. 


\section{Orthoceras strictum R. Br.}

The small genus Orthoceras shares many floral features with Diuris and is therefore placed in subtribe Diuridinae (Dressler 1993), differing from the latter genus most obviously in its horn-like and spreading lateral sepals and minute petals. O. strictum, from Australia, New Zealand and New Caledonia has erect inflorescences with a few small resupinate flowers. Its gynostemium ontogeny has been examined. Staminode primordia can be seen in early and middle stages (Fig. 4F). Staminodes are prominent throughout ontogeny and develop directly into the large tooth-like lateral gynostemium appendages which are visible in late stages and in the mature gynostemium (Fig. 4H-I). An obscure dorsolateral tooth reminiscent of an auricle was observed in one gynostemium in a middle stage (illustrated in Kurzweil 1998, Fig. 11F). However, this bulge does not appear to be a constant feature as many gynostemia without it were also observed. An obscure dorsal process is also visible in the adult gynostemium at the base of the large staminodes (arrowhead in Fig. 4I), and it is possible that it is derived from such an auricle. In addition, there is also a ventral bulge at the base of the staminodes in late stages and in the mature flower (? in Fig. 4I). Due to its very late ontogenetic origin it is most probably only a secondary outgrowth of the staminodes. The median carpel apex is obscurely three-lobed in middle and late ontogeny (Fig. 4G-H). Lateral carpel apices emerge as separate structures but soon become connate into an emarginate ridge.

\section{Calochilus campestris $\mathrm{R}$. Br.}

Calochilus is a genus of approximately 18 species (Jones 1988; Jones \& Lavarack 1989; Jones \& Gray 2002; Jones \& Clements 2004). All species have a single fleshy leaf up to $40 \mathrm{~cm}$ long. Fertile plants produce a raceme 20 to $100 \mathrm{~cm}$ tall bearing two to sixteen resupinate flowers. Most species have multicellular hair-like processes that cover the surface and margins of the obscurely three-lobed labellum; these are usually green, red, crimson or purple in colour. These floral features give rise to their common name 'Beardies' or 'Bearded Orchids', and their scientific name 'Calos' meaning beautiful, and 'cheilos' meaning lip (Jones, 1988).

In C. campestris, the mature gynostemium is short and arched forward. Column-wings are present but obscure and fused to the anther filament to form a mitra or hood, which dorsally covers the gynostemium. The apex of the anther is narrowly elongate with a terminal, subacute connective process visible in the early and middle developmental stages (Fig. 6A), becoming obtuse and densely papillate in late developmental stages (Fig. 6B). Staminode primordia are clearly visible in early stages and are already connate, forming a mitra (Mi in Fig. 6A, C). The mitra later grows up to the base of the anther (Mi in Fig. 6C, D, F). Mature apices of the mitra are covered with tuberculate appendages and are likely to be homologous with auricles (arrowhead in Fig. 6C-D). During the middle stages of development the auricles become heavily sculptured (arrowhead in Fig. 6E-F). During late developmental stages, two orbicular bulges form on the ventral surface of the mitra, on both sides of the base of the stigma (g in Fig. 6F). Their anatomical homology and function are unknown but they form the prominent gland-like "eyes" of the mature flower. The median carpel apex is strongly elongate ( $\mathrm{mc}$ in Fig. 6A, F) and connate to the lateral carpel apices, appearing three-lobed in all stages observed. In mature flowers, a viscidium forms on the ventral surface of the median carpel apex ( $\mathrm{mc}$ in Fig. 6F). 


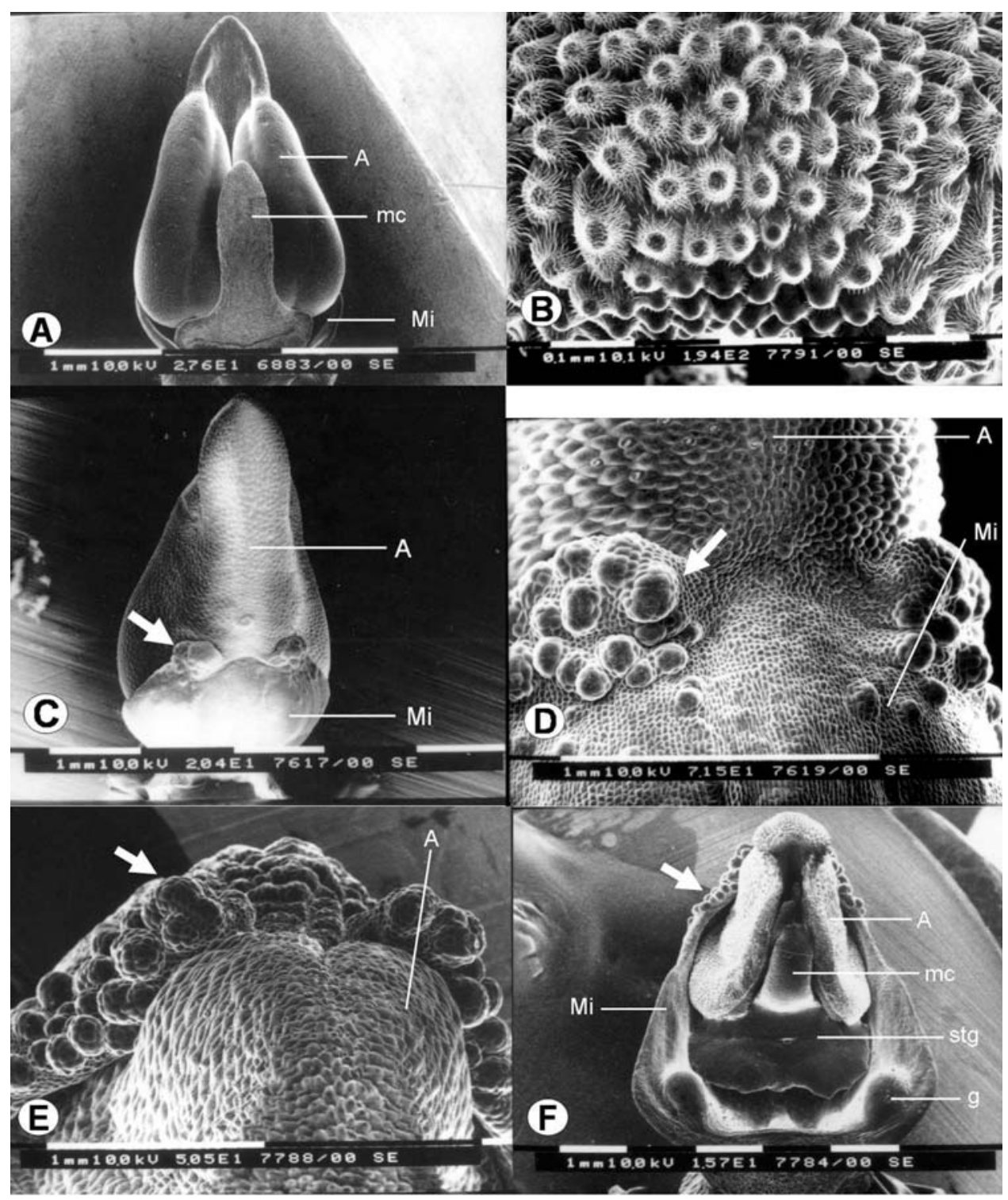

Fig. 6. Gynostemium of Calochilus campestris in different developmental stages. A, during early development in front view; $\mathbf{B}$, papillae on connective apex during late development; $\mathbf{C}$, during early development in dorsal view; D, during middle development in dorsal view; E, auricles during late development in front view; $\mathbf{F}$, during anthesis in front view. - SEM micrographs. Bars: $1 \mathrm{~mm}$ in A, C-F; $0.1 \mathrm{~mm}$ in B. Abbreviations: $\mathrm{A}=$ anther, $\mathrm{Mi}=$ mitra, $\mathrm{mc}=$ median carpel apex, $\mathrm{g}=$ glandlike "eyes" on mitra, stg = stigma. The arrowheads mark suspected auricles (= filament appendages; see Kurzweil 1987b). Sources: NSW446115. 


\section{Acianthus fornicatus R. Br.}

The genus Acianthus, as re-circumscribed by Jones et al. (2002), includes eight species in Australia and New Zealand. A. fornicatus from New South Wales and Queensland has erect inflorescences with a few small resupinate flowers. The sepals and the petals are free, unlobed and spreading. The ovate lip is unstalked and bears a median callus. A long column-part is present in the knee-like bent gynostemium. Lateral gynostemium appendages (column-wings) are rather small. Small staminode primordia are visible in early ontogeny (Fig. 7A) and later develop into the small lateral appendages of the mature gynostemium as seen in Fig. 7D. Structures likely to be auricles are not visible in any stage. A prominent feature of the ontogeny is the median carpel apex which is conspicuously three-lobed in middle stages with its lobes roughly equally long (Fig. 7B). Its central lobe loses its prominent appearance later on and grows into the gap between the two thecae which is reminiscent of the intrathecal rostellum portion of tribe Orchideae (Fig. 7C-D). The lateral carpel apices emerge connate to an undivided edge and also remain undivided later on (not shown). The anther is apically emarginate throughout ontogeny.

\section{Pterostylis concinna R. Br.}

A single species of the large genus Pterostylis (subtribe Pterostylidinae sensu Jones \& Clements 2002 - about 120 species in Australia, New Zealand, New Guinea and New Caledonia) was available for study, and is of considerable interest as it is the only study species outside tribe Diurideae, having been transferred to tribe Cranichideae recently (Pridgeon et al. 2003). The terminal inflorescences bear a single or a few resupinate flowers with a prominent galea made up of median sepal and petals, two basally fused lateral sepals and a mobile lip. In P. concinna the slender and curved gynostemium has a long column-part. Large lateral gynostemium appendages (column-wings) are present in the apical portion and are expanded next to the anther so that they almost obscure it. They consist of rather wide and obtuse lobes pointing down, and narrow and acute lobes pointing up. The stigma of the mature gynostemium is an entire pad at the base of the column-part. Early stages of the gynostemium ontogeny of this species were not available for study. In a middle stage ('three-carpel-apex stage') the large anther is erect and the three carpel apices are visible with the median one being as usually the largest (Fig. 7E). Prominent staminode primordia are clearly visible in this stage. As could be expected they develop directly into the large apical wings of the late stages and the mature gynostemium (Fig. 7E-I). From the ontogeny it is evident that both the acute upper and the obtuse lower part of the mature lateral gynostemium appendages are derived from these staminodes. In middle ontogenetic stages there is also an insignificant suspected auricle visible (arrowhead in Fig. $7 \mathrm{H}$ ), and in the mature gynostemium the structure takes the shape of an obscure small tooth next to the anther (arrowhead in Fig. 7I). The median carpel apex is an obscurely three-lobed organ in middle ontogeny (Fig. 7F-G). Lateral carpel apices are separate structures soon after their initiation and remain separate until the column-part starts elongating.

\section{Discussion}

The ontogeny of the anther and the three carpel apices, as well as the late formation of the gynostemium of the species examined here, conform basically with that of all other 

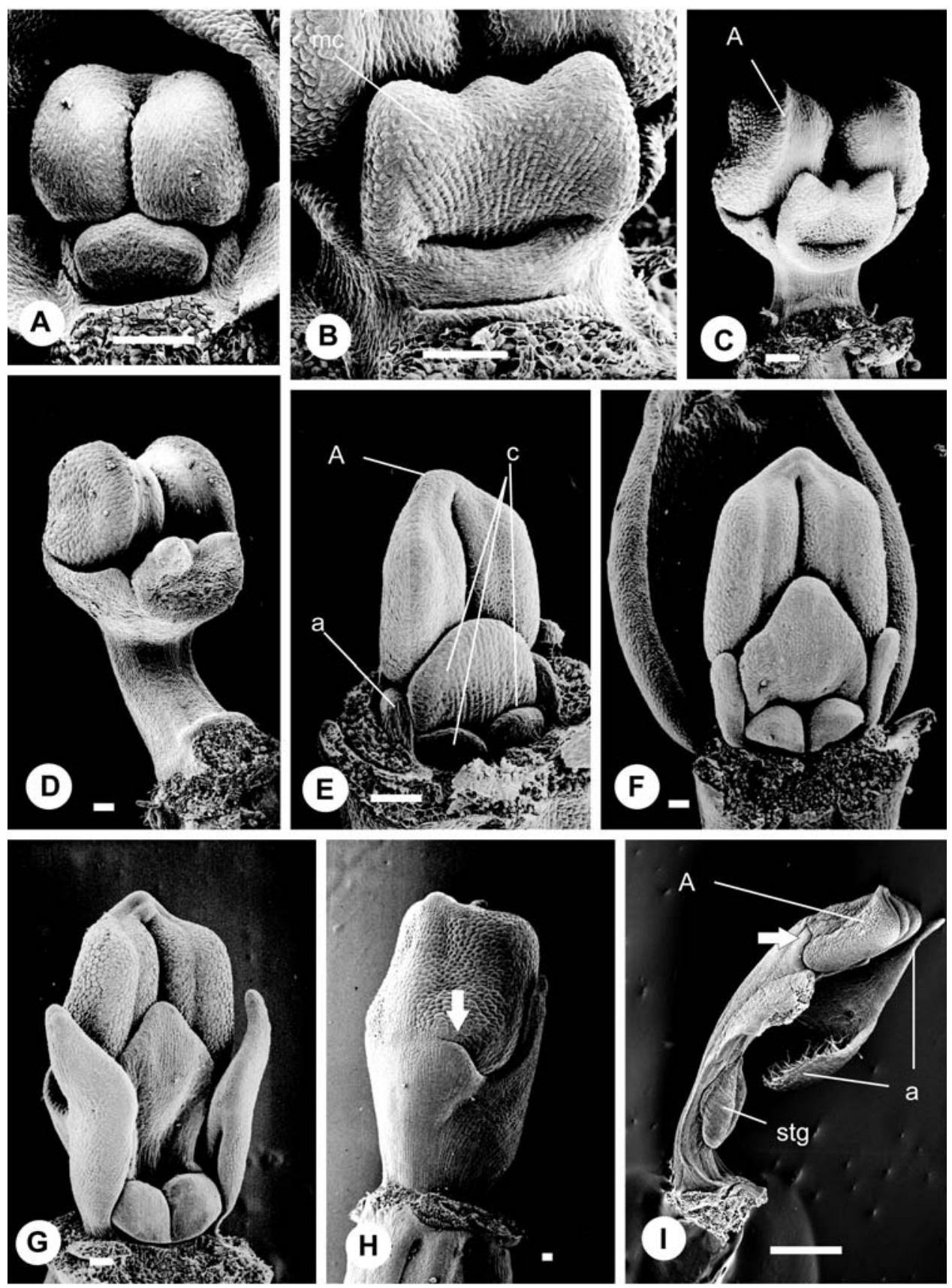

Fig. 7. Gynostemium development of various species. A-D. Acianthus fornicatus. Gynostemium/base of gynostemium in front view. E-I. Pterostylis concinna. E-G. Font views. H. Side view. I. Adult gynostemium in side view with the left lateral gynostemium appendage removed. - SEM micrographs. Bars: $0.1 \mathrm{~mm}$ in $\mathrm{A}-\mathrm{H} ; 1 \mathrm{~mm}$ in I. Abbreviations: $\mathrm{A}=$ anther, $\mathrm{a}=$ staminodes, $\mathrm{c}=$ carpel apices, $\mathrm{mc}=$ median carpel apex 
monandrous orchids studied so far (e.g. Irmisch 1842; Payer 1859; Wolf 1865; Pfitzer 1888; Capeder 1898; Heusser 1915; Hirmer 1920; Jeyanayaghy \& Rao 1966; Rao 1967; Sattler 1973; Yang 1982; Rasmussen 1982, 1985b; Kurzweil, several papers; Leins et al. 1988; Schill et al. 1992; Linder \& Kurzweil 1996; Luo \& Chen 2000).

The anther is the first organ of the gynostemium to become visible. Like the six perianth organs, it develops from the marginal parts of a transversally elliptic floral primordium. The anther is erect in early stages and the gap between its two thecae is of very early ontogenetic origin. As in other orchids it is the largest organ of the gynostemium throughout early development, but in many species its growth later decreases; the anther is therefore often comparatively small in the mature gynostemium.

The three carpel apices emerge in front of the anther in early ontogeny and later develop directly into the stigma lobes of the mature flower. The median carpel apex is the first carpel apex to be initiated. It is erect and unlobed in early stages, and measures approximately $3 / 4$ of the width of the anther soon after its initiation. It remains the largest carpel apex in the early and middle ontogeny, but like the anther it often loses its prominent appearance later on and is fairly small in the mature flower. Its apical portion becomes structurally modified in late ontogeny and develops into the rostellum. The derivation of the non-receptive rostellum from the median carpel apex is also found in all other orchids examined so far. The two lateral carpel apices emerge just after the median one in a position directly in front of it. Just after their initiation they are either separate (Genoplesium fimbriatum, Pterostylis concinna, Cryptostylis erecta, Orthoceras strictum) or connate into an entire or emarginate ridge (Rimacola elliptica, Acianthus fornicatus, Diuris longifolia, Thelymitra carnea, Calochilus campestris). Both these character states are also found in the other orchids (Kurzweil 1998; Kurzweil \& Kocyan 2002). The lateral carpel apices are initially about one third to half as wide as the median carpel apex which is clearly visible where the lateral carpel apices are separate or connate into an emarginate ridge. On the basis of outgroup comparisons with other basally diverging families of Asparagales, the most recent common ancestor of the orchids probably had three spreading stigma lobes, and therefore the separate emergence of the lateral carpel apices is most likely the more primitive condition for the family as a whole. In late ontogeny the two lateral stigma lobes are generally basally united and also marginally fused with the median stigma lobe to form a funnel-like structure. Finally, the lateral stigma lobes develop into the receptive stigma and also a portion of varying size is contributed by the median stigma lobe. The surface of the stigma is papillose in the late stages.

In some species the organ-complex of the three stigma lobes is elevated together with the anther and the column-wings in that the common base of all of these organs elongates, and thus the column-part of the gynostemium is formed. The formation of this column-part takes place in the late stages. The resulting gynostemium can be very long (e.g. Rimacola elliptica, Caleana major, Pterostylis concinna, Acianthus fornicatus). The fusion may also be absent or very weak and is then confined to the base of the organs of the gynostemium (Genoplesium fimbriatum, Diuris longifolia, Orthoceras strictum). The weak fusion of the gynostemium in Diuris, Orthoceras and Genoplesium has been thought to be a primitive condition (see Dressler 1986: 10). However, recent molecular phylogenetic analyses of the Diurideae and outgroups (Kores et al. 2000, 2001; Clements et al. 2002) strongly imply that weak fusion has been secondarily derived in these taxa. Such a reversal is readily explicable as the result of neotenic loss 
of gynostemium fusion and elongation late in floral organogeny. In the other monandrous orchids the parts of the gynostemium are completely fused, and very elongate column-parts occur in Epidendroideae and two genera in the the Orchidoideae-Diseae: Satyrium and Pachites.

\section{Lateral gynostemium appendages}

Of particular interest are the lateral gynostemium appendages which are often referred to as column-wings in floristic and taxonomic works. It was found that they are ontogenetically directly derived from massive bulges superposed to the petals which can be observed in early and middle ontogeny. On account of their early initiation and the position in front of the petals they are here interpreted as vestiges of the lateral stamens of the inner staminal whorl (i.e. staminodes in a position $a_{1}$ and $a_{2}$ ) which corresponds well with most other Orchidaceae (e.g., Kurzweil 1987a, 1988). Previously, similar prominent staminodes were also observed and illustrated in middle stages of the gynostemium development of Gavilea glandulifera, a member of the tribe Chloraeeae, and the diurids Diuris punctata, Prasophyllum concinnum and Microtis parviflora (Rasmussen 1982). Since orchids have most probably evolved from ancestors with 3+ 3 stamens (see also Rasmussen 1982) the presence of pronounced staminodes must be interpreted as an ancestral feature in each of the two clades of monandrous orchids, the Vanilloideae and Orchidoideae-Epidendroideae. The primitive feature of massive staminodes has apparently constantly been retained in the orchid subfamily Epidendroideae (Kurzweil 1998; Kurzweil \& Kocyan 2002). Interestingly, in Epidendroideae the staminodes sometimes disappear in late ontogeny as they become incorporated into the gynostemium. In most species of tribes Cranichideae, Diseae and Orchideae (sensu Pridgeon et al. 2001, 2003) the staminodes $\mathrm{a}_{1}$ and $\mathrm{a}_{2}$ are small or obscure in early ontogeny (Kurzweil 1987b, 1988). Given the sister group relationship between Diurideae and Cranichideae-Chloraeeae on the one hand and Diseae and Orchideae on the other (Kores et al. 2001; Chase et al. 2001) staminode reduction has probably evolved independently in Cranichideae and OrchideaeDiseae.

In a few species examined here there are also additional lateral gynostemium appendages which become visible in middle developmental stages. They are initiated as small or obscure but clearly visible bulges in a dorsolateral position on the anther. Their time of initiation and place of origin corresponds well with that of the filament appendages termed auricles of tribe Orchideae (Kurzweil 1987b; Luo \& Chen 2000), and the structures are here also interpreted as such. The homology of the auricles of Orchideae with filament appendages was originally suggested by Vermeulen (1966) whose investigations were based on the study of adult and especially teratological flowers. In Orthoceras strictum such auricles are not constant in their appearance. This points to the possibility that the auricles may be genetically fixed even if they are externally not always expressed. In superficial appearance the auricles observed here are mostly unsculptured, differing from those of Orchideae which are usually strongly sculptured. In the present study heavily sculptured auricles were only observed in Lyperanthus suaveolens and Calochilus campestris, and previously a heavily sculptured auricle was illustrated in an unidentified Calochilus species (Kurzweil 1998, Fig. 11L). No sign of any auricles was here found in Acianthus fornicatus, Cryptostylis erecta, Chiloglottis sp., Corybas fimbriatus and Microtis parviflora. Auricles in Diurideae have been reported before by Dressler (1986: cladogram on p. 13) although it is not clear whether the term was used in the sense of filament appendages (however, Dressler 
included Chloraeinae in his tribe Diurideae which are now recognised as a distinct tribe Chloraeeae; Pridgeon et al. 2003). In other orchids, auricles have so far only been reported in tribes Orchideae and Diseae. While they are usually prominent in Orchideae they are mostly small and reduced in Diseae. The only exception known as yet is the genus Bartholina (Orchideae) where the auricles are absent (Kurzweil \& Weber 1991), and this is probably the result of secondary loss in this genus. The shared occurrence of auricles in Diurideae, Orchideae + Diseae, Chloraeeae and Pterostylis, a basally diverging lineage of Cranichideae, is most parsimoniously interpreted as a synapomorphy for these tribes that has been secondarily lost in most Cranichideae.

The appearance of the auricles in the mature flowers differs among the species examined. In Genoplesium fimbriatum the staminodes and the auricles become fused in the course of development while their common base elongates. These two organs together develop into the prominent lateral gynostemium appendages (columnwings) which are therefore of dual origin. The auricles of Rimacola elliptica develop into small processes on top of the staminodial wings. In Caleana major and Diuris longifolia prominent auricles were not observed in early and middle stages but the lateral appendages of the late-ontogenetic gynostemium have a small apical tooth or are shallowly two-lobed, respectively. Compared with the other species examined here this may again suggest an involvement of both staminodes and auricles, although there is obviously no clear ontogenetic evidence for a dual origin. The auricles of Pterostylis concinna are small lobes next to the anther behind the column-wings. Previously, a distinct two-lobing of the lateral gynostemium appendages was found in middle developmental stages in Gavilea glandulifera and Prasophyllum concinnum but a possible ontogenetic derivation from two different structures was not suspected (Rasmussen 1982). In view of the present findings the two-lobing found in these two species may be suggestive of the origin from both staminodes and auricles. It is also noteworthy that the dorsal lobe of the lateral gynostemium appendages of Prasophyllum concinnum is said to contain raphides (Rasmussen 1982) which is an anatomical feature frequently associated with auricles. In other orchids, a dual origin of the lateral gynostemium appendages is common in Orchideae where the auricles are frequently heavily sculptured appendages on top of or at the posterior end of a staminodial base (Kurzweil 1987b, 1990; Kurzweil \& Weber 1991, 1992; Luo \& Chen 2000).

\section{Three-lobing of the median carpel apex}

It was found that the median carpel apex of Acianthus fornicatus, Calochilus campestris and Corybas fimbriatus is clearly three-lobed in middle developmental stages, and Genoplesium fimbriatum, Caleana major, Pterostylis concinna, Microtis parviflora and Orthoceras strictum have a shallowly three-lobed median carpel apex in this stage. This is remarkable as the vast majority of Orchidaceae have an unlobed median carpel apex throughout middle and late development, which is apparently the basic condition in the family. The three-lobing observed here is reminiscent of tribes Orchideae and Diseae where the median carpel apex is usually deeply three-lobed throughout ontogeny (Vogel 1959; Vermeulen 1959, 1966; Dressler 1981, 1993; Kurzweil, several papers) although it has been reduced to a two-lobed or unlobed structure in some Diseae (Kurzweil 1991, 1996; Linder \& Kurzweil 1996). This shared feature might be another morphological synapomorphy for the Orchidoideae, albeit one that has been secondarily lost in a number of different lineages. 
Alternatively, the three-lobing of the median carpel apex observed here may also merely be a precondition for the formation of an apical viscidium in late ontogeny, and is therefore not necessarily evidence of phylogenetic relationship. However, this explanation is unlikely as one would not expect this feature to already be expressed early in ontogeny.

\section{Phylogenetic considerations}

The phylogenetic relationships and the delimitation of diurid orchids have been rather disputed among taxonomists.

In the past the diurid orchids were often treated in a subgroup of Orchidaceae that contains terrestrial orchids with a large number of primitive characters (e.g. 'Acrotonae-Polychondreae', Schlechter 1926; 'Neottioideae', Garay 1960, 1972; 'Epidendroideae-Contribe Neottianthae', Vermeulen 1966; 'Neottioideae', Brieger et al. 1970-2000). After realising that this group is an artificial aggregation that contains several basally diverging lineages of both Orchidoideae and Epidendroideae (e.g. Rasmussen 1982; Dressler 1993; Cameron et al. 1999), its tribes and subtribes were either transferred to other subfamilies or raised to the rank of separate new subdivisions (e.g. subfamily Spiranthoideae; Dressler 1979, 1981, 1993). Although the diurid orchids, as circumscribed by Dressler $(1981,1993)$, were in the past treated as a natural group, it is now evident that they are not monophyletic (Kores et al. 1997, 2000; Cameron et al. 1999; Molvray et al. 2000; Pridgeon et al. 2001). Groups which do not belong to the core clade of diurid orchids are the Pterostylis and Chloraea groups.

A relationship of the diurid orchids with the Orchideae and Diseae (subfamily Orchidoideae) is now widely accepted on the basis of morphological and anatomical data (Dressler 1979, 1981, 1993; Rasmussen 1985a; Pridgeon et al. 2001) and was also confirmed by molecular investigations (Kores et al. 1997, 2000; Cameron et al. 1999; Molvray et al. 2000). The most frequently cited morphological feature shared by diurid orchids on the one hand and Orchideae and Diseae on the other are root tubers. Some authors have expressed doubt about the homology of these structures because of their anatomical diversity (see Pridgeon \& Chase 1995 and references therein). However, the unusual structural similarities that the root tubers of all of these groups share prompted Dressler (1993) and Pridgeon \& Chase (1995) to postulate their homology. An implication of this idea in the light of more recently published molecular phylogenetic analyses (Kores et al. 1997, 2000; Cameron et al. 1999; Molvray et al. 2000 ) is that root tubers are a synapomorphy for the subfamily Orchidoideae but that they have been secondarily lost in several different lineages.

\section{Conclusions}

Two interesting similarities shared by Diurideae and Pterostylis (Cranichideae) with tribes Orchideae and Diseae were found in the present study, namely the auricles and the early three-lobing of the median carpel apex, which add further support to the theory of a close relationship of the groups.

A) Definite auricles or obscure structures suggestive of such auricles were here found in eight of 11 species where the early or middle ontogeny was examined. Auricles of diurid orchids have been observed before but due to the lack of ontogenetic 
studies the similarity in their ontogeny to the auricles of the Orchideae and Diseae was not noted.

B) The second point of interest relates to the early three-lobing of the median carpel apex in six of the 11 species where relevant stages were observed. The median carpel apex is frequently only shallowly lobed but in three species the three-lobing is rather pronounced.

An extensive discussion of the systematics of the diurid orchids which is based on morphological-ontogenetic gynostemium characters would obviously require far more complete sampling.

\section{Acknowledgments}

Collecting was made possible with a permit from the NSW National Parks and Wildlife Service (license no. A2409) which is gratefully acknowledged. The first author would also like to express his gratitude to Ruth Rudkin, Alan Dash, Wal and Gill Upton, Jim Lycos, Graeme Bradburn, John Riley, Darryl Smedley and Andrew Harvie for their assistance during a fieldtrip to the Sydney region. The second author would like to thank the late Tony Bishop for company and assistance in the field while collecting material for this study. We also thank the staff of the Electron Microscope Unit of the University of Cape Town (Figures 1-5, 7) and the University of Sydney (Figure 6) for providing SEM time and for technical support.

\section{References}

Bernhardt P (1993) Caleana. Pp. 194-195 in GJ Harden (ed.), Flora of New South Wales, Vol. 4 (New South Wales University Press: Sydney)

Bower C (2001) Tribe Diurideae, pollination. Pp. 59-213 in AM Pridgeon, PJ Cribb, MW Chase \& FN Rasmussen (eds) Genera Orchidacearum, vol. 2 (Oxford University Press: Oxford)

Brieger FG, Maatsch R, \& Senghas K (1970-2000) Die Orchideen - R. Schlechter, $3^{\text {rd }}$ ed. (Paul Parey: Berlin)

Cameron KM, Chase MW, Whitten WM, Kores PJ, Jarrell DC, Albert VA, Yukawa T, Hills HG \& Goldman DH (1999) A phylogenetic analysis of the Orchidaceae: evidence from RBCL nucleotide sequences. American Journal of Botany 86: 208-224.

Capeder E (1898) Beiträge zur Entwicklungsgeschichte einiger Orchideen. Flora 85: 368-423.

Chase MW, Kurzweil H, Linder P \& Cribb PJ (2001) Phylogenetics of Orchidoideae. Pp. 7-9 in Pridgeon AM, Cribb PJ, Chase MW \& Rasmussen FN (eds) Genera Orchidacearum, vol. 2 (Oxford University Press: Oxford)

Clements MA, Jones DL, Sharma IK, Nightingale ME, Garratt MJ, Fitzgerald KJ, Mackenzie AM \& Molloy BPJ (2002) Phylogenetics of Diurideae (Orchidaceae) based on the internal transcribed spacer (ITS) regions of nuclear ribosomal DNA. Lindleyana 17: 135-171.

de Pinna MCC (1991) Concepts and tests of homology in the cladistic paradigm. Cladistics 7: 367-394.

Dressler RL (1979) The subfamilies of the Orchidaceae. Selbyana 5: 197-206.

Dressler RL (1981) The orchids - natural history and classification (Harvard University Press: Cambridge, Massachusetts and London)

Dressler RL (1986) Recent advances in orchid phylogeny. Lindleyana 1: 5-20.

Dressler RL (1993) Phylogeny and classification of the orchid family (Cambridge University Press)

Garay LA (1960) On the origin of the Orchidaceae. Botanical Museum Leaflets [Harvard University] 19: $57-96$. 
Garay LA (1972) On the origin of the Orchidaceae II. Journal of the Arnold Arboretum 53: $202-215$.

Gerstberger P \& Leins P (1978) Rasterelektronenmikroskopische Untersuchungen an Blütenknospen von Physalis philadelphica (Solanaceae). Berichte der Deutschen Botanischen Gesellschaft 91: 381-387.

Heusser K (1915) Die Entwicklung der generativen Organe von Himantoglossum hircinum Spr. Beihefte zum Botanischen Centralblatt 32, 1. Abt.: 218-277.

Hirmer M (1920) Beiträge zur Organographie der Orchideenblüte. Flora 113: 213-310.

Irmisch T (1842) Bemerkungen über die Epipactis-Arten der deutschen Flora. Linnaea 16: $417-462$.

Jeyanayaghy S \& Rao AN 1966. Flower and seed development in Bromheadia finlaysoniana. Bulletin of the Torrey Botanical Club 93: 97-103.

Jones DL (1988) Native Orchids of Australia (Read Books: Sydney)

Jones DL (2001) Tribe Diurideae, distributions of the genera. Pp. 59-213, in A.M. Pridgeon AM, Cribb PJ, Chase MW \& Rasmussen FN (eds) Genera Orchidacearum, vol. 2 (Oxford University Press: Oxford)

Jones DL \& Clements MA (2002) A review of Pterostylis (Orchidaceae). Australian Orchid Research 4.

Jones DL \& Clements MA (2004) Miscellaneous new species, new genera, reinstated genera and new combinations in Australian Orchidaceae. The Orchadian, Scientific Supplement 14(8).

Jones DL \& Gray B (2002) Calochilus ammobius (Orchidaceae). The Orchadian 14(2): 85-86.

Jones DL \& Lavarack PS (1989) New Species of Calochilus (Orchidaceae) from North-Eastern Queensland. Proceedings of the Royal Society of Queensland 100: 101.

Jones DL, Clements MA, Sharma IK, Mackenzie AM \& Molloy BPJ (2002) Nomenclatural notes arising from studies into the tribe Diurideae (Orchidaceae). The Orchadian 13: 437-468.

Kores PJ, Cameron KM, Molvray M \& Chase MW (1997) The phylogenetic relationships of Orchidoideae and Spiranthoideae (Orchidaceae) as inferred from $r b c \mathrm{~L}$ plastid sequences. Lindleyana 12: 1-11.

Kores PJ, Weston PH, Molvray M \& Chase MW (2000) Phylogenetic relationships within the Diurideae (Orchidaceae): inferences from plastid MATK DNA sequences. Pp. 449-456, in Wilson KL \& Morrison DA (eds) Monocots: systematics and evolution (CSIRO: Collingwood)

Kores PJ, Molvray M, Weston PH, Hopper SD, Brown A, Cameron KM \& Chase MW (2001) A phylogenetic analysis of Diurideae (Orchidaceae) based on plastid DNA sequence data. American Journal of Botany 88: 1903-1914.

Kurzweil H (1985) Entwicklungsgeschichtliche Untersuchungen an Orchideenblüten, unter besonderer Berücksichtigung des Gynostemiums (unpublished $\mathrm{Ph}$. D. thesis, University of Vienna.

Kurzweil H (1987a) Developmental studies in orchid flowers I: epidendroid and vandoid species. Nordic Journal of Botany 7: 427-442.

Kurzweil,H (1987b) Developmental studies in orchid flowers II: orchidoid species. Nordic Journal of Botany 7: 443-451.

Kurzweil H (1988) Developmental studies in orchid flowers III: neottioid species. Nordic Journal of Botany 8: 271-282.

Kurzweil H (1990) Floral morphology in Orchidaceae subtribe Disinae. Botanical Journal of the Linnean Society 102: 61-83.

Kurzweil H (1991) The unusual structure of the gynostemium of the Orchidaceae-Coryciinae. Botanische Jahrbücher für Systematik 112: 273-293.

Kurzweil H (1996) Floral morphology and ontogeny in subtribe Satyriinae (Orchidaceae). Flora 191: 9-28.

Kurzweil H (1998) Floral ontogeny of orchids: a review. Beiträge zur Biologie der Pflanzen 71: 45-100.

Kurzweil H \& Kocyan A (2002) Ontogeny of orchid flowers. Pp. 2-138, in J. Arditti (ed) Orchid Biology - Reviews and Perspectives (Kluwer Academic Publishers: Dordrecht, Netherlands)

Kurzweil H \& Weber A (1991) Floral morphology of southern African Orchideae. I. Orchidinae. Nordic Journal of Botany 11: 155-178.

Kurzweil H \& Weber A (1992) Floral morphology of southern African Orchideae. II. Habenariinae. Nordic Journal of Botany 12: 39-61. 
Leins P, Tucker SC \& Endress PK (1988) Aspects of floral development (J. Cramer/Gebrüder Bornträger: Berlin)

Linder HP \& Kurzweil H (1996) Ontogeny and phylogeny of Brownleea (Orchidoideae: Orchidaceae). Nordic Journal of Botany 16: 345-357.

Luo Y-B \& Chen S-C (2000) The floral morphology and ontogeny of some Chinese representatives of orchid subtribe Orchidinae. Botanical Journal of the Linnean Society 134: 529-548.

Molvray M, Kores PJ \& Chase MW (2000). Polyphyly of mycoheterotrophic orchids and functional influences on floral and molecular characters. Pp. 441-448, in Wilson KL \& Morrison DA (eds) Monocots: systematics and evolution (CSIRO: Collingwood)

Payer J-B (1857) Traite d' Organographie comparée de la fleur (Paris)

Perkins AJ (2001) Phylogenetic Systematics of the Genus Calochilus (Orchidaceae). (unpublished Ph.D. thesis, University of Sydney, Australia)

Pfitzer E (1888) Untersuchungen über Bau und Entwicklung der Orchideenblühte. I. Theil: Cypripedilinae, Ophrydinae, Neottiinae. Pringsheim Jahrbuch für die wissenschaftliche Botanik 19: 155-177.

Pridgeon AM \& Chase MW (1995) Subterranean axes in tribe Diurideae (Orchidaceae): morphology, anatomy, and systematic significance. American Journal of Botany 82: 1473-1495.

Pridgeon AM, Cribb PJ, Chase MW \& Rasmussen FN (eds) (2001) Genera Orchidacearum, vol. 2 (Oxford University Press: Oxford)

Pridgeon AM, Cribb PJ, Chase MW \& Rasmussen FN (eds) (2003) Genera Orchidacearum, vol. 3 (Oxford University Press: Oxford)

Rao AN (1967) Flower and seed development in Arundina graminifolia. Phytomorphology 17: $291-300$.

Rasmussen FN (1982) The gynostemium of the neottioid orchids. Opera Botanica 65: 1-96.

Rasmussen FN (1985a). Orchids. Pp. 249-274, in Dahlgren RMT, Clifford HT \& Yeo PF (eds) The families of the Monocotyledons (Springer Verlag: Berlin, Heidelberg, New York, Tokyo)

Rasmussen FN (1985b) The gynostemium of Bulbophyllum ecornutum (J.J. Smith) J.J. Smith (Orchidaceae). Botanical Journal of the Linnean Society 91: 447-456.

Sattler R (1973) Organogenesis of flowers (University of Toronto Press: Toronto)

Schill R, Dannenbaum C \& Eckert C (1992) Zur Blütenentwicklung von Thecostele alata (Roxb.) Par. et Rchb. f. 1874 (Orchidaceae). Flora 186: 271-285.

Schlechter R (1926) Das System der Orchidaceen. Notitzblatt des Botanischen Gartens und Museum zu Berlin-Dahlem 88, 9: 563-591.

Vermeulen P (1959) The different structure of the rostellum in Ophrydeae and Neottieae. Acta Botanica Neerlandica 8: 338-355.

Vermeulen P (1966) The system of the Orchidales. Acta Botanica Neerlandica 15: 224-253.

Vogel S (1959) Organographie der Blüten kapländischer Ophrydeen. Akademie der Wissenschaften und der Literatur, Abhandlungen der Mathematisch-Naturwissenschaftlichen Klasse 6-7: 268-532.

Weston PH (1988) Indirect and Direct Methods in Systematics. Pp. 27-56, in Humphries CJ (ed.) Ontogeny and Systematics (Columbia University Press: New York)

Weston PH (1994) Methods for rooting cladistic trees. Pp. 125-155, in Siebert DJ, Scotland RW \& Williams DM (eds) Models in phylogeny reconstruction (Oxford University Press: Oxford)

Wolf T (1865) Beiträge zur Entwicklungsgeschichte der Orchideenblüte. Pringsheim Jahrbuch für die wissenschaftliche Botanik 4: 261-384.

Yang S-H (1982) Studies on the development of flower in Gastrodia elata Bl. Acta Botanica Sinica 24: 21-27. (in Chinese language)

Manuscript received 13 July 2004, accepted 28 April 2005 


\section{Appendix: List of material studied}

The following list cites all specimens which have been studied in their floral ontogeny. In most cases herbarium vouchers were deposited in the herbarium of the Royal Botanic Gardens Sydney (NSW). The nomenclature follows mainly Jones (1988). PHW is an abbreviation for the second author of the paper, P.H. Weston; NSW indicates a number in the National Herbarium of New South Wales.

Acianthus fornicatus R. Br. - PHW 1393

Caladenia carnea R. Br. - Kurzweil 1928

C. catenata (Smith) Druce - Abell 67

Caleana major R. Br. - PHW 1229, Kurzweil s.n.

Calochilus campestris R. Br. - NSW446115

C. robertsonii Benth. - Abell 72

Chiloglottis sp. - PHW 1278

Corybas fimbriatus (R. Br.) Rchb. f. - PHW 1392

Cryptostylis erecta R. Br. - PHW 2473

Diuris longifolia R. Br. - sine collector

Eriochilus autumnalis R. Br. - PHW 1382

Genoplesium fimbriatum R. Br. - PHW 1277, PHW s.n.

Glossodia minor R. Br. - PHW 1235, PHW 1401

Lyperanthus suaveolens R. Br. - PHW 1224

Microtis parviflora R. Br. - PHW 1251

Orthoceras strictum R. Br. - PHW 1271, PHW 1279, PHW 1584

Pterostylis concinna R. Br. - PHW 1398

Rimacola elliptica (R. Br.) Rupp - Bishop J67/31-37, PHW 1586

Thelymitra carnea R. Br. - PHW 1227, PHW 1232, PHW 1242, PHW 1404 